\title{
Syringomyelia in association with a neurofibroma of the filum terminale
}

\author{
M. R. GOODING
}

From the Wessex Neurological Centre, Southampton

SUMMARY A case of neurofibroma of the filum terminale associated with syringomyelia is described. The relationship of spinal cord tumours and syringomyelia is discussed and a possible mode of formation of the syrinx in the present case is suggested.

The association of syringomyelia with intraspinal tumours has been well established during the past 100 years. The present case is being reported because of the unusual findings of a large syringomyelic cavity of the cord together with an apparently anatomically unconnected neurofibroma of the filum terminale.

\section{CASE REPORT}

A 15 year old girl was admitted to the Wessex Neurological Unit in April 1970 (case no. 10327) with a three year history of lower lumbar pain. This pain was constant and aggravated by standing, walking, and coughing. In January 1970 she became aware of the gradual onset of an inconstant burning pain in the upper lumbar region radiating around both loins into the left hypochondrium, which was aggravated by the same factors as before. During the next four months she developed a progressive weakness affecting first the left and soon after the right lower limbs. Two weeks before her admission her urinary flow became impaired with an intermittent and variable stream.

\section{EXAMINATION}

The configuration and range of movements of the spinal column were normal. Abdominal reflexes were absent and there was moderate weakness of the left and slight weakness of the right lower limbs such that she could stand and walk only with assistance (grades 3 and 4 respectively). Tone was symmetrically increased in both lower limbs and bilateral ankle clonus and extensor plantar responses were present. Pain and temperature sense on both sides of the trunk and of the right lower limb below the level of T7 dermatome were impaired, with the relative preservation of all sensory modalities of the left $\overrightarrow{0}$ lower limb. General examination was normal; blood pressure was $120 / 80 \mathrm{~mm} \mathrm{Hg}$.

\section{INVESTIGATIONS}

Chest radiographs were normal. Radiographs of the whole spine showed generalized narrowing of the $\rightarrow$ pedicles and widening of the interpedunculas or distance from the T3 vertebral level to a transitiona vertebra (L6). The thoracic and lumbar vertebrat 웅 bodies also showed marked scalloping (Fig. 1f Cisternal gas myelography demonstrated a norma cervical cord but gas would not pass beyond the upper thoracic region. Cisternal positive contras myelography using $3 \mathrm{ml}$. iophendylate (Ethiodat confirmed the presence of a block at the level of $T \overline{5} \mathrm{~N}$ vertebral body. Analysis of the cisternal cerebrospinal fluid (CSF) obtained at this examination showed $120 \mathrm{mg}$ protein, $62 \mathrm{mg}$ glucose $/ 100 \mathrm{ml}$., and 4 lymphocytes/c.mm.

Lumbar myelography using $6 \mathrm{ml}$. iophendylate outlined a continuous sac extending from T7 to L3 vertebra containing a $4 \mathrm{~cm} \times 3 \mathrm{~cm}$ mass preventing filling of the lumbosacral space below this level, although later rescreening showed that contrast medium did pass below the lumbar lesion (Fig. 2). The radiological diagnosis was an expanded cord extending from T3 vertebra to the lower thoracic region. There was also an extramedullary, intradural mass at the L3 vertebral level.

Examination of the xanthochromic fluid obtained by lumbar puncture at this time showed a protein content of $4.7 \mathrm{~g} / 100 \mathrm{ml}$. with a large excess of $\bigcirc$ globulin, glucose $62 \mathrm{mg} / 100 \mathrm{ml}$., and 1 lymphocyte/ c.mm.

FIRST OPERATION (May 1970: Mr. John Garfield) In view of the clinical and radiographic findings it 


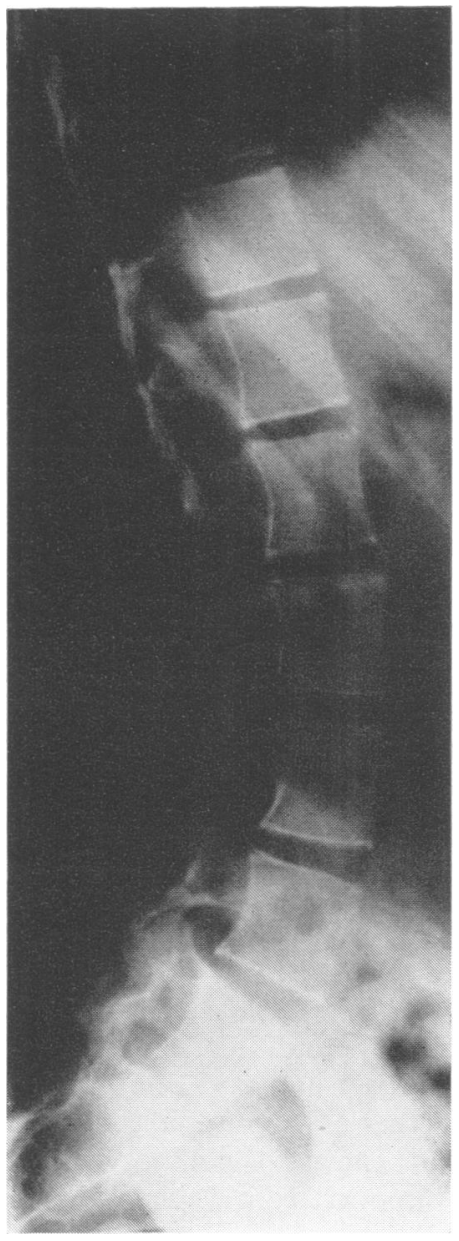

FIG. 1. Lateral radiograph showing scalloping of the thoracolumbar vertebrae.

was decided to perform a laminectomy from T4-6 inclusive. A fullness of the dura mater extending downwards from T5 vertebra could be seen and when the dura mater was opened marked expansion of the cord was confirmed. A sharp needle was inserted in the midline of the cord at the level of maximum swelling and $25 \mathrm{ml}$. clear yellow fluid obtained with resultant collapse of the cord.

This fluid was reported upon by Professor J. N. Cumings (Institute of Neurology, Queen Square) to contain (normal CSF values in parentheses):

Total protein $(15-20 \mathrm{mg} / 100 \mathrm{ml}$.), $4.6 \mathrm{~g} / 100 \mathrm{ml}$. Alkaline phosphatase ( 0 i.u./l.), 44 i.u./l. Cholesterol (less than $1 \mathrm{mg} / 100 \mathrm{ml}$.), $88 \mathrm{mg} / 100 \mathrm{ml}$. Phosphohexerose isomerase (0 i.u./l.), 83 i.u./l. Lactic dehydrogenase (0-10 i.u./l.), 35 i.u./l.

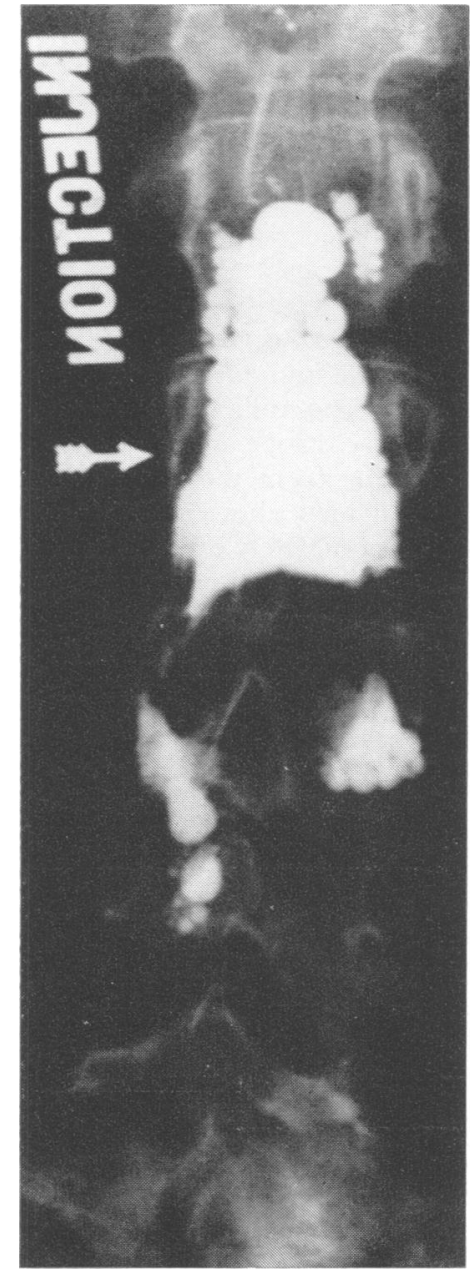

FIG. 2. Myelographic appearances of the tumour situated at L3.

Professor Cumings suggested that these findings were consistent with a cyst within a relatively benign tumour and would not be obtained from cerebrospinal fluid.

Progress The patient's immediate postoperative recovery was satisfactory, but on the fifth day she complained of weakness and paraesthesiae of both hands; examination revealed severe weakness of both lower limbs (grade 0 on the left and grade 1 on the right). There was weakness throughout the right upper limb with sensory loss from C6-T3 dermatomes on that side, there being a band from T3-7 dermatomes in which sensation was normal and below that the sensory level was as previously 
described. Thereafter there was only gradual and barely significant improvement in the power of her lower limbs.

SECOND OPERATION (5 June 1970: Mr. John Garfield) The deterioration of the patient's condition was attributed to a block occurring at the level of the previously demonstrated intradural lumbar mass and accordingly a laminectomy was made from L2-4 inclusive. On opening the dura mater, a firm solid tumour adherent to the nerve roots was seen. The tumour was freed from the surrounding nerve roots and it became apparent that it was arising from the filum terminale. This structure was divided above and below the mass, which was then completely excised. It was clear that the tumour lay in a cystic cavity, which contained yellow fluid and droplets of iophendylate, the upper part of which was removed establishing free communication between the cavity and the sub-arachnoid space.

Histology The tumour measured $2.8 \mathrm{~cm} \times 1.8 \mathrm{~cm}$ and was enclosed in a thin intact capsule. On section it was largely solid but contained some necrotic areas. It was vascular with numerous thin- and thick-walled blood vessels distributed irregularly through a cellular stroma which was sometimes reticular and elsewhere arranged in interweaving bundles. Nuclear palisading was occasionally a feature of the latter. There was no evidence of rapid growth or malignant change.

The stromal cells produced reticulin.

A pathological diagnosis of neurofibroma was made.

After the second operation she made good progress and within two weeks she had regained full bladder control, increased power of her lower limbs, and she was beginning to walk. The appreciation of sensation below the level of T6 dermatome was improving, while her upper limbs had returned to normal.

Examination six months later showed that she had continued to improve, bladder control remained normal, and her gait was excellent. Sensation was normal apart from a band of hypoaesthesia over the T10 and T11 segments on the left side of her trunk. The plantar responses were still extensor.

\section{DISCUSSION}

The generally accepted pathological description of syringomyelia is of a longitudinal cavitation of the spinal cord or brain-stem in which the cavity may be unrelated to the central canal and is lined at least in part by glial tissue. Recent work (Gardner, McCormack, and Dohn, 1960; Gardner, 1965) relates the aetiology of syringo- $\mathbb{\mathbb { D }}$ myelia to the failure of the exit foramina of the o fourth ventricle to develop during embryonic life. In these circumstances there is a water hammer effect on the cerebrospinal fluid in the central canal of the spinal cord, which subse- $\stackrel{\rho}{\stackrel{S}{~}}$ quently dilates. Tamaki and Lubin (1938) suggested that syringomyelia was the result of cavitation in glial tissue following the imperfect $\overrightarrow{\vec{s}}$ development of the central canal. A vascular basis has been put forward by some authors; $\frac{C}{O}$ Russell (1932) considered that there was evidence $\frac{\bar{c}}{\sigma}$ of anaemia and haemolytic softening in her $\stackrel{\mathbb{Q}}{\AA}$ cases, as did Wolf and Wilens (1934), whereas o Tauber and Langworthy (1935) ascribed the $\vec{\circ}$ syrinx to vascular insufficiency due to vascular anomalies.

In their reports of syringomyelia and intraspinal tumours many authors have discussed the pathological significance of the frequent associa- iv tion of the two conditions, Simon (1875) was $\rightarrow$ perhaps the first to suggest that syringomyelia of was possibly the result of softening occurring spinal cord 'gliomas'.

Baumler (1887) in his series of 96 cases syringomyelia found that 17 of these had intramedullary tumour. Dimitroff (1897) scribed 12 cases of tumour in 84 cases of syringe myelia that came to necropsy, these figures receiving support from Poser (1956) who collected 245 cases of syringomyelia from the literature and found that $40(16.4 \%)$ of these were proven at necropsy to have an intramedullary tumour.

In their description of 301 cases of primary intramedullary tumour, Slooff, Kernohan, and MacCarty (1964) found that in the 33 cases which came to necropsy, 19 were associated with syringomyelia, as were six of Hamby's (1944) cases and two of Russell's (1932) three patients. Poser (1956) reviewed 209 cases of intramedullary tumour reported in the literature and found that $65(31 \%)$ were associated with syringomyelia. He concluded that the discrepancy between the incidence of intramedullary tumour in syringomyelia and of $\frac{D}{O}$ syringomyelia in cases of intramedullary tumour might be because, where intramedullary tumour $N$ was diagnosed at operation, these cases were $N$ 
excluded from the syringomyelia studies and were included in the tumour series.

The tumour types associated with syringomyelia would appear to be neurofibroma, meningioma, ependymoma, and glioma (Kernohan and Sayre, 1952; Poser, 1956; Slooff et al., 1964) less frequently teratoma, haemangioblastoma (Russell, 1932), lipoma, chordoma, and dermoid. Multiple heterotypic tumours have been described (Tamaki and Lubin, 1938; Poser, 1956), these being usually ependymomas and neurofibromas or meningiomas and Poser (1956) thought that they were formes frustes of Lindau's disease.

In all series of cases of tumour associated with syringomyelia, the authors have commented on the apparent continuity of the two lesions. Slooff et al. (1964) described one case (no. 24) where there was an ependymoma of the cauda equina with an anatomically separate cord cyst extending from T4-T12 segments. Poser (1956) could find only $21(11.3 \%)$ of the 155 cases described in the literature where there was no relationship between the tumour and the syrinx and it is difficult to avoid his conclusion that in some of these cases, rather than having a causal relationship, the two conditions are the divergent results of a single basic process.

There is little doubt that in some cases the syringomyelia is due to the extension of a cystic cavity lying within the tumour, and is directly due to an extension of the tumour proliferation, as is manifest in spinal ependymomas. However, equally clearly, no single hypothesis so far suggested offers a completely satisfactory answer for the occurrence of syringomyelia, and MacKay and Favill's (1935) comment that a combination of several factors may be necessary seems indisputable. They considered that the syrinx was the end result of a pathological process originating with malformation of the dorsal median septum leading to gliosis and vascular proliferation and followed by ischaemia. When tumour formation was present this was merely a more active process of the same glial elements.

The present case has two features of interest. Firstly, the syringomyelic cavity was found both on myelography and at operation not to extend above the level of T5 cord segment and it is unlikely that Gardner's (1965) suggested mode of syrinx formation would apply in this case.
Furthermore, the syringomyelic cavity appeared to be in direct communication with the subarachnoid space, as the protein content of this cavity was the same as that found in the lumbosacral sac, and shows some common features with one of the patients reported in the series of Ellertsson and Greitz (1969). Secondly, the neurofibroma was quite separate from the syringomyelic cavity and examination of the filum terminale confirmed the absence of a connecting channel between the two lesions.

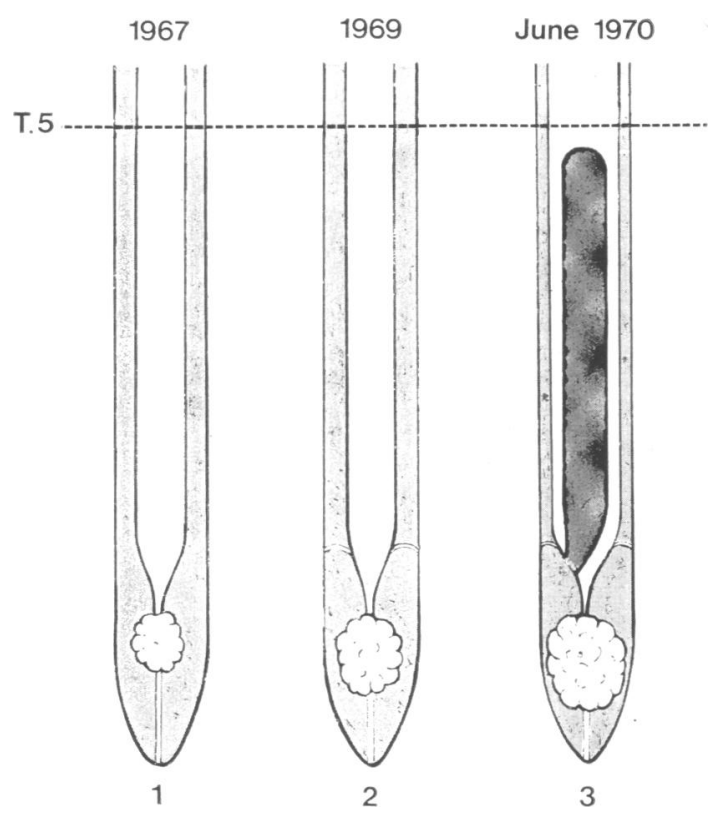

FIG. 3. Suggested mechanism of development of syringomyelia in the present case.

Assuming that the pathogenesis of these two lesions is connected, it would seem probable that the initial lesion was the neurofibroma forming in the filum terminale with a secondary cyst formation below the conus medullaris, this lesion causing the lower lumbar pain which persisted for three years. The onset of the upper lumbar pain radiating into the left hypochondrium, which was of quite different character and associated with a progressive paraparesis and micturition difficulties, may be attributed to the 
extension of the cyst into the cord substance from the conus to the T5 segmental level when the block occurred at the lumbar level (Fig. 3).

It is possible that the syrinx in the present patient was due to the presence of an unproven ependymoma, but the occurrence of multiple heterotypic tumours with an associated syringomyelia is extremely uncommon. The continued improvement of the patient after surgery is encouraging but it will be several years before an ependymoma can be excluded on clinical grounds.

I wish to thank Mr. John Garfield and Dr. P. K. Robinson, under whose care this patient was admitted, for their permission to report this case.

\section{REFERENCES}

Bäumler, A. (1887). Ueber Höhlenbildungen im Rückenmark. Deutsches Archiv für Klinische Medizin, 40, 443-543.

Dimitroff, S. (1897). Ueber Syringomyelie. Archives of Psychiatry, 29, 299-339.

Ellertsson, K. B., and Greitz, T. (1969). Myelocystographic and fluorescein studies to demonstrate communication between intramedullary cysts and the cerebrospinal fluid space. Acta Neurologica Scandinavica, 45, 418-430.

Gardner, W. J., McCormack, L. J., and Dohn, D. F. (1960). Embryonal atresia of the fourth ventricle. The cause of 'arachnoid cyst' of the cerebellopontine angle. Journal of Neurosurgery, 17, 226-237.
Gardner, W. J. (1965). Hydrodynamic mechanism of syringomyelia: its relationship to myelocele. Journal of 으 Neurology, Neurosurgery, and Psychiatry, 28, 247-259.

Hamby, W. B. (1944). Tumors in the spinal canal in childhood. II. Analysis of the literature of a subsequent decade (1933-1942); report of a case of meningitis due to an intramedullary epidermoid communicating with a dermal $\underset{\widehat{Q}}{\bar{O}}$ sinus. Journal of Neuropathology and Experimental Neurology, 3, 397-412.

Kernohan, J. W., and Sayre, G. P. (1952). Tumors of the central nervous system. In Atlas of Tumor Pathology. Fascicles 35 and 37. Armed Forces Institute of Pathology: Washington, D.C.

Mackay, R. P., and Favill, J. (1935). Syringomyelia and intramedullary tumor of the spinal cord. Archives of $\overline{\mathrm{O}}$ Neurology and Psychiatry, 33, 1255-1278.

Poser, C. M. (1956). The Relationship between Syringomyelia and Neoplasm. Thomas: Springfield, Ill.

Russell, D. S. (1932). Capillary haemangioma of spinal cord associated with syringomyelia. Journal of Pathology and Bacteriology, 35, 103-112.

Simon, Th. (1875). Beiträge zur Pathologie und pathologischen Anatomie des Central-Nervensystem. Archiv für $\vec{\circ}$ Psychiatrie, 5, 108-163.

Slooff, J. L., Kernohan, J. W., and MacCarty, C. S. (1964). $\overrightarrow{\vec{\omega}}$ Primary Intramedullary Tumors of the Spinal Cord and $\omega$ Filum Terminale. Saunders: Philadelphia.

Tamaki, K., and Lubin, A. J. (1938). Pathogenesis of syringomyelia. Case illustrating the process of cavity? formation from embryonic cell rests. Archives of Neurology ow and Psychiatry, 40, 748-761.

Tauber, E. S., and Langworthy, O. R. (1935). A study of $^{\circ}$ syringomyelia and the formation of cavities in the sping of cord. Journal of Nervous and Mental Disease, 81, 245-26

Wolf, A., and Wilens, S. L. (1934). Multiple hemangiळ 윽 blastomas of the spinal cord with syringomyelia. American Journal of Pathology, 10, 545-567. 